\title{
Niches for Extramedullary Hematopoiesis in the Spleen
}

The spleen is a major site for extramedullary hematopoiesis and adult mouse and human spleens retain low numbers of hematopoietic stem cells (HSC). Hematopoiesis is however dependent on stromal microenvironments that provide appropriate molecular signals. Recent evidence now suggests that a distinct stromal cell type exists in the spleen which can function as a niche for hematopoiesis. This review considers the role of the spleen in hematopoiesis, and the possibility that the spleen can be utilized or amplified as a site for hematopoiesis during HSC transplantation. If stromal cells can be isolated and used to expand HSC in vitro, or provided as an ectopic niche in vivo for the same purpose, then the potential exists to enhance hematopoiesis in patients undergoing myeloablative treatment, HSC transplantation or involution of lymphoid tissue with ageing.

Key words: Niche, hematopoiesis, hematopoietic stem cells, stroma, spleen

Research School of Biology, Australian National University, Canberra, Australia

Submitted : 22.03 .2012 Accepted: 27.03 .2012

Correspondence: Prof. Dr. Helen C. O’Neil Division of Biomedica Sciences\&Biochemistry, Research School of Biology, The Australian National University, Canberra ACT 0200, Australia

Phone: +61261254720

E-mail: Helen.ONeill@anu.edu.au

OCopyright 2012 by Cellular Therapy and Regenerative Medicine Society Available on-line at www.nichejournal.org

\section{Introduction}

Bone marrow (BM) is a rich source of HSC and for decades bone marrow transplants have provided HSC for regeneration of the hematopoietic system in humans. HSC arise in the embryo from an hemangioblast present in the yolk sac and aortagonad-mesonephros. They then appear in the fetal liver and spleen, entering the bone marrow at a late stage during embryogenesis. They are maintained for life in BM, spleen and liver of mice (1), and have been detected in BM and spleen of adult humans (2). HSC have distinguishing properties of self-renewal, asymmetric cell division, and ability to clonally regenerate all hematopoietic cell types (3). The methodology for sorting HSC from BM using specific antibodies and flow cytometry has become a standard technique in many labs $(4,5)$. The HSC subset is however heterogeneous, comprising cells with long term and short term reconstitution capacity $(6,7)$. Longterm HSC are commonly isolated from mouse BM or spleen as lineage (Lin) ${ }^{-} \mathrm{Sca}-1^{+} \mathrm{C}-$ kit $^{+}$Flt $3^{-}$cells (6), and can be further purified as the CD150+CD48- subset of Lin-Sca ${ }^{+}{ }^{+} \mathrm{Ckit}^{+} \mathrm{BM}(8,9)$. Epigenetic imprinting of HSC also contributes to differences in hematopoietic potential (10). Given the level of heterogeneity amongst HSC, it is important to consider them in relation to their niche of origin, their distinct hematopoietic potential, and to use this knowledge to inform HSC transplantation in the clinic. Most studies have concentrated on the more prevalent $\mathrm{HSC}$ in $\mathrm{BM}$ with less attention given to HSC in extramedullary sites like spleen or liver.

While hematopoietic niche elements in BM have been defined as osteoblasts, endothelial cells and perivascular reticular cells, there has been little consideration of the stromal elements which form niches for HSC in the spleen. Former work from this lab has identified a unique stromal cell type which supports hematopoiesis in vitro from overlaid HSC. Based on this finding, the hypothesis is advanced that the spleen contains a unique mesenchymal cell type which independently functions as a niche for HSC, supporting HSC maintenance, self-renewal and differentiation. Another hypothesis is that progenitors of these stromal cells could seed ectopic niches for long-term support of hematopoiesis. Artificial or ectopic lymph nodes have been developed with biocompatible scaffolds supporting tissue formation. However, extension of that technology into the splenic model will be entirely dependent on identification of the appropriate stromal cells, or their progenitors, to seed scaffolds.

\section{The Spleen in Hematopoiesis}

Spleen is a secondary lymphoid organ essential for $\mathrm{T}$ and $\mathrm{B}$ cell immunity to blood-borne antigens. While neonatally splenectomised mice were once thought to display apparently normal hematopoietic development, a specific role for the spleen in immunity is demonstrated by evidence 
that asplenic humans have enhanced susceptibility to infection with encapsulated bacteria such as Streptococcus (11). Its importance in immunity can be demonstrated following splenectomy in humans. Subsequent autotransplantion of the spleen onto the omentum has been shown to preserve splenic immune function (12). The fact that transplanted spleen fragments can regenerate by reforming stromal cell networks and filling with lymphoid and other hematopoietic cells, (13) recommends the spleen in humans as an important target in regenerative medicine. Most studies on the role of the spleen in extramedullary hematopoiesis have involved the murine model. While the human spleen is functionally similar in terms of immune cell development, the marginal zone surrounding the white pulp region is structurally distinct from murine spleen (14). In the human spleen, an inner and outer marginal zone is surrounded by a large perifollicular zone which separates the follicular marginal zone from the red pulp. This forms part of the open circulation of the spleen and lymphocytes enter the white pulp without crossing an endothelial layer. Rodents have a marginal sinus that separates the marginal zone from the follicles, and lymphocytes enter the spleen through the marginal sinus where they bind to endothelial cells and migrate across the marginal zone. Despite these differences, human and murine spleens contain many equivalent lymphoid, myeloid and stromal cell types, and demonstrate similar immune functional potential.

An historical view is that the spleen contributes mainly to erythroid cell development, undergoing hematopoiesis only at times of stress or myeloablation (15). The spleen microenvironment also supports the later development of myeloid and dendritic cells, such that subsets like plasmacytoid dendritic cells (DC), conventional DC and monocytes develop from BM-derived precursors entering the spleen from blood (16). The spleen is now recognized to be an important site for extramedullary hematopoiesis, and small numbers of HSC can migrate through blood and lymph entering the spleen, and other tissues like the liver, lung and brain (17). The number of migrating HSC increases following acute inflammation or drug treatment which induces their mobilization $(18,19)$. Adult mice have been found to retain primitive longterm reconstituting HSC in the spleen and liver, albeit in far lower numbers than in bone marrow $(1,20)$. Similarly, low numbers of hematopoietic stem/progenitor cells (HSPC) were recently detected in adult spleens of pigs, baboons and humans (2). Spleens of mice and humans therefore retain low numbers of HSC and represent appropriate microenvironments for extramedullary hematopoiesis at least under conditions of stress or inflammation.

A related issue is whether the spleen in the resting state maintains endogenous HSC which self-renew and differentiate within the spleen, and contribute to steady-state hematopoiesis. Indeed, HSC in murine spleen reflect multipotent longterm selfrenewing stem cells similar to those found in BM $(1,20)$. In reconstitution studies in mice, splenic HSC gave full hematopoietic reconstitution of myeloid, dendritic and lymphoid cells for up to 51 weeks post transplantation (20). Recently, a single stromal cell type was isolated from murine spleen that was shown to support HSC self-renewal and differentiation in vitro $(21,22)$. This finding invokes a model whereby spleen stromal cells maintain endog- enous hematopoietic progenitors that undergo myelopoiesis in vitro to produce a tissue-specific antigen presenting cell (named L-DC) (23-25). The in vivo equivalent of this subset has since been identified as a novel subset of myeloid dendritic-like cells in the spleen distinct from other known DC and myeloid subsets (26). The spleen thus appears to contribute in a tissue-specific manner to hematopoiesis in the resting state. The finding that the spleen supports development of a novel antigen presenting cell type unique to the spleen is not without precedence, and tissuespecific antigen presenting cells have been described previously in skin (27) and brain (28), supporting the compartmentalisation of the immune system.

When spleen-derived HSC were used to reconstitute irradiated host mice, they were found to have different hematopoietic potential from BM-derived $\mathrm{HSC}$, producing higher relative numbers of L-DC compared with other subsets of dendritic and myeloid cells $(20,29)$. While others have reported equal reconstitution potential for both spleen- and BM-derived HSC, those studies did not compare the development of individual DC/myeloid subsets (30). The hematopoietic potential of HSC may therefore differ with tissue origin, such that the spleen can generate cells not produced within the BM microenvironment. This could be a property endogenous to the stem cell, or could be imprinted by the microenvironment in which HSC develop.

\section{Stromal Cell Niches Support Hematopoiesis}

In BM, stromal cells regulate hematopoiesis by providing structural support through a network of connective tissue of mesenchymal, and more specifically, osteoblastic and endothelial origin. Stromal niches support the maintenance and self-renewal of HSC, and the differentiation and lineage commitment of hematopoietic progeny (31). Cell contact between HSC and stromal cells is essential, and hematopoiesis is mimicked only poorly in vitro by cocktails of soluble factors (32). The niche provides essential signals for HSC maintenance and self-renewal. The Hedgehog, Wnt and Notch pathways are known regulators of HSC self-renewal, and bone morphogenic protein 4, transforming growth factor- $\beta$ and stem cell factor also support HSC development (33). Essential niche elements have been described as osteoblastic in BM, vascular or endothelial in $B M$ and the spleen $(8,34,35)$, and more recently as perivascular in $\mathrm{BM}$, comprising distinct mesenchymal progenitor cells (36). During HSC mobilization, endothelial cells in or near sinusoidal vessels in BM release developing stem cells into blood (8). Similarly, engraftment of HSC into the spleen occurs in contact with sinusoidal venous endothelium (8).

Most studies on hematopoiesis have investigated osteoblastic niches in BM, and vascular or perivascular niches are not well described. Osteoblastic niches are characterised by the expression of osteopontin, osterix, N-cadherin and tie-2; $(37,38)$ all known regulators of hematopoiesis. The importance of bone-forming cells in hematopoiesis is supported by evidence that ectopic HSC niches form under the kidney capsule of mice upon transplantation with either subendothelial stromal cells from BM, or a subset of fetal bone cells $(38,39)$. These ectopic niches recruit HSC and endothelial cells, and maintain longterm HSC for 4-5 weeks. Endochondreal ossification or bone formation appears to be necessary for formation of a vascularised niche in bone (38). In contrast, 
hematopoiesis in the spleen, fetal liver and other extramedullary sites occurs in the absence of bone-forming osteoblastic cells. An important question is whether signals for vascularisation, and for HSC maintenance and self-renewal, are provided by a distinct stromal cell type in these tissues. Another consideration is whether HSC in non-bone-forming tissues represent a distinct subset with different signalling requirements for their differentiation.

There is now increasing support for the role of perivascular stromal cells in HSC development in the BM of both mice and humans (36). These distinct cells have been termed variably adventitial reticular cells (ARC), mesenchymal stem cells or osteoprogenitors in humans (39). In mice, they have been described as CXCL12-abundant reticular (CAR) cells (40). In humans, they have been aligned with pericytes or mural cells which surround the vascular endothelium (41), and reflect multipotent osteoprogenitors with osteogenic and adipogenic differentiative potential (42). Recently they were described as Leptin receptor-expressing perivascular stromal cells, which, together with endothelial cells, provide an essential source of stem cell factor for HSC development (43). This cell type in BM appears to be heterogeneous, but equivalent or similar cells have not yet been described in the spleen.

\section{Characterisation of Splenic Stroma That Support Hematopoiesis}

Stromal cell components of lymphoid tissues have been difficult to characterise in the absence of definitive cell surface markers, and most studies have involved cultured stromal cell lines rather than freshly isolated cell subsets. While murine fetal liver stromal lines can support HSC maintenance in vitro $(44,45)$, BM stromal lines have been disappointing as niche models, but this could reflect the low frequency of competent stromal cells in BM. Splenic stromal lines that support HSC maintenance and myelopoiesis in vitro can be readily isolated from longterm stroma-dependent spleen cultures which also support continuous in vitro hematopoiesis $(23,46)$. The STX3 line, and its cloned derivatives, was first characterised as an atypical or immature endothelial cell type in mice (22). STX3 cells produce high levels of CXCL12, a factor that recruits HSC into BM niches, $(40,47)$ and expresses markers common to endothelial cells like CD90, CD34, COL18a1, CD164, FLT1, MCAM and VCAM, although not CD31, a marker of mature vascular endothelial cells $(21,48)$. STX3 clones such as 5G3, 2A8, $10 C 9$ and 3B5 have endothelial-like morphology, and all but 3B5 support hematopoiesis in BM overlaid above stroma (22).

STX3 co-cultures of lineage-depleted BM cells, or purified BMderived HSC, now provide a direct test of the hematopoietic support capacity of splenic stromal cell lines $(24,49)$. The cell type produced in co-cultures over the $5 \mathrm{G} 3$ clone of STX3 resembles the L-DC subset of antigen presenting cells described previously as endogenous to the spleen (26). Similarly, Lin ${ }^{-1}$ kit $^{+}$HSPC isolated from the spleen were found to colonise $5 \mathrm{G} 3$ co-cultures for longterm production of L-DC (25). Equivalent human spleen stromal lines have now been derived from splenic LTC. These resemble the murine lines and appear to support the production of cells resembling L-DC from overlaid BM cells (data in preparation). Indeed, there appears to be similarity between human and murine spleens in that they harbor HSC, and contain stromal cells that support hematopoiesis. While the murine model is more amenable to study, follow-on human studies appear feasible.
While HSC have been localized in murine spleen in contact with sinusoids in the red pulp area (8), it is not known how those niches contribute to hematopoiesis, or the nature of any stromal cell types involved. While osteoprogenitors are essential for the establishment of HSC niches in BM, HSC also develop in the embryo, and in the adult spleen and liver, in the apparent absence of osteogenesis. While secondary lymphoid tissues have been well characterised in terms of mature stromal cell components and their role in lymphopoiesis, the role of stromal cells in extramedullary hematopoiesis has not been documented. Splenic stroma represents a mixed population including vascular and lymphatic endothelial cells, marginal zone macrophages, follicular DC, fibroblastic reticular cells, marginal reticular cells and red pulp fibroblasts $(50,51)$. However, the location of any mesenchymal stem/progenitor cells, or indeed osteogenic or endothelial progenitor cells, has not yet been investigated in the spleen. While markers of mesenchymal cells are known, most are not unique to one cell type and may also be expressed by hematopoietic or endothelial cells. The expression of markers common to STX 3 and its cloned lines could be used to benefit the characterization and isolation of stromal cell fractions for further study. Any subsets of interest could also be functionally assessed for their in vitro hematopoietic support capacity for production of L-DC.

\section{Production of Ectopic Splenic Niches or Artificial Spleens}

If stromal cells supporting hematopoiesis in the spleen can be identified and isolated, then it should be possible to reengineer the spleen microenvironment for enhanced hematopoietic output. Previous work with long-term spleen cultures and stromal co-cultures support a niche model involving only one stromal cell type. One possibility is that HSC numbers could be amplified ahead of transplantation by culture above competent stroma. Another approach is to expand the niche space for hematopoiesis. Ectopic splenic niches can be established under the kidney capsule of mice following transplantation of spleen capsules, spleen fragments, or in vitro grown stromal cells embedded in collagen sponges $(13,52,53)$. The subcapsular region of the kidney has proven a successful site for transplantation due to its high vasculature, and because the kidney contains no HSC (38). Neonatal 7-day spleen fragments engrafted under the kidney capsule of splenectomised mice showed reconstitution with donor type hematopoietic cells (52). Grafts retained donor-type HSC, evident by development of donor-type myeloid cells over 2 to 4 weeks. Host type HSC, lymphocytes and myeloid cells were also recruited into grafts (52). Others have reported engraftment and reconstitution of irradiated adult and neonatal spleen for up to 3 months, although that model could not assess hematopoiesis arising from endogenous HSC (54). Ideally, ectopic niches could be generated using isolated splenic stromal cells embedded in artificial matrices as a support structure for tissue formation. Indeed, advances have already been made with the synthesis of artificial lymph nodes $(55,56)$ and the spleen $(57)$, where biocompatible scaffolds support ectopic tissue formation. A number of studies support a deterministic role for a single splenic stromal cell type in the formation of HSC niches in the spleen. The lineage origin of those stromal cells as endothelial or mesenchymal cells, and their status as mature cells versus progenitors, is not yet clear. Their relationship with similar niches in BM is also unknown. The ability of candidate stromal cells to successfully form an ectopic niche 
would depend on the formation of a vascular network and their ability to maintain HSC and support hematopoiesis.

One hypothesis is that the spleen maintains a progenitor population that seeds the formation of stroma constituting the HSC niche. Another is that these are readily isolated as constituents of blood or BM. There have been several reports of potential endothelial progenitors in cord blood, fetal blood, peripheral blood $(58,59)$ and also adult BM $(60)$. Mesenchymal stem/progenitors are also present in BM and enter blood upon mobilization of BM stem cells (61). Indeed, progenitors would represent important candidates for the establishment of long-term ectopic niches in patients through their capacity to continuously regenerate stroma.

\section{Conclusion}

Demonstration that artificial hematopoietic niches can be established in vivo, become colonized by HSC and then support hematopoiesis, would represent significant advances. Successful production of artificial or ectopic spleens however depends on the isolation and transplantation of splenic stromal cells which support hematopoiesis. The challenge therefore exists to identify the mesenchymal or endothelial progenitors in the spleen, blood and BM that give rise to stromal cells, and so regenerate hematopoietic niches in the spleen and other organs. If stromal cells or their progenitors can be harvested for engraftment of 'artificial niches' ahead of HSC transplantation, then this type of stem cell therapy could have considerable significance for enhancement of hematopoiesis in HSC transplant patients.

\section{Acknowledgements}

This work was supported in part by funding from the National Health and Medical Research Council of Australia (project grant \#585443). The author is grateful to Sawang Petvises for permission to reference his unpublished data.

Conflict of interest: No conflict of interest was declared by the authors.

\section{References}

1. Wolber FM, Leonard E, Michael S, Orschell-Traycoff CM, Yoder MC, Srour EF. Roles of spleen and liver in development of the murine hematopoietic system. Experimental Hematology 2002; 30: 1010-9. [Crossref]

2. Dor FJ, Ramirez ML, Parmar K, Altman EL, Huang CA, Down JD, et al. Primitive hematopoietic cell populations reside in the spleen: Studies in the pig, baboon, and human. Experimental Hematology 2006; 34: 1573-82. [Crossref]

3. Morrison SJ, Wandycz AM, Hemmati HD, Wright DE, Weissman IL. Identification of a lineage of multipotent hematopoietic progenitors. Development 1997; 124: 1929-39.

4. Baum CM, Weissman IL, Tsukamoto AS, Buckle AM, Peault B. Isolation of a candidate human hematopoietic stem-cell population. Proceedings of the National Academy of Sciences of the United States of America 1992; 89: 2804-8. [Crossref]

5. Spangrude GJ, Heimfeld S, Weissman IL. Purification and characterization of mouse hematopoietic stem cells. Science 1988; 241: 58-62. [Crossref]

6. Christensen JL, Wright DE, Wagers AJ, Weissman IL. Circulation and chemotaxis of fetal hematopoietic stem cells. PLoS Biology 2004; 2: E75. [Crossref]
7. Foudi $A$, Hochedlinger $K$, Van Buren $D$, Schindler JW, Jaenisch R, Carey V, et al. Analysis of histone 2B-GFP retention reveals slowly cycling hematopoietic stem cells. Nature Biotechnology 2009; 27: 84-90. [Crossref]

8. Kiel MJ, Yilmaz OH, Iwashita T, Terhorst C, Morrison SJ. SLAM family receptors distinguish hematopoietic stem and progenitor cells and reveal endothelial niches for stem cells. Cell 2005; 121: 1109-21. [Crossref]

9. Papathanasiou P, Attema JL, Karsunky H, Xu J, Smale ST, Weissman IL. Evaluation of the long-term reconstituting subset of hematopoietic stem cells with CD150. Stem Cells 2009; 27: 2498-508. [Crossref]

10. Attema JL, Papathanasiou P, Forsberg EC, Xu J, Smale ST, Weissman IL. Epigenetic characterization of hematopoietic stem cell differentiation using miniChIP and bisulfite sequencing analysis. Proceedings of the National Academy of Sciences of the United States of America 2007; 104: 12371-6. [Crossref]

11. Brendolan A, Rosado MM, Carsetti R, Selleri L, Dear TN. Development and function of the mammalian spleen. BioEssays : news and reviews in molecular, cellular and developmental biology 2007; 29: 166-77.

12. Yamataka A, Fujiwara T, Tsuchioka T, Kurosu Y, Sunagawa M. Heterotopic splenic autotransplantation in a neonate with splenic rupture, leading to normal splenic function. Journal of pediatric surgery 1996; 31: 239-40. [Crossref]

13. Pabst R, Westermann J, Rothkotter HJ. Immunoarchitecture of regenerated splenic and lymph node transplants. International review of cytology 1991; 128: 215-60. [Crossref]

14. Mebius RE, Kraal G. Structure and function of the spleen. Nature reviews Immunology 2005; 5: 606-16. [Crossref]

15. Yanai N, Satoh T, Obinata M. Endothelial cells create a hematopoietic inductive microenvironment preferential to erythropoiesis in the mouse spleen. Cell structure and function 1991; 16: 87-93. [Crossref]

16. Liu K, Victora GD, Schwickert TA, Guermonprez P, Meredith MM, Yao $\mathrm{K}$, et al. In vivo analysis of dendritic cell development and homeostasis. Science 2009; 324: 392-7.

17. Massberg S, Schaerli P, Knezevic-Maramica I, Köllnberger M, Tubo N, Moseman EA, et al. Immunosurveillance by hematopoietic progenitor cells trafficking through blood, lymph, and peripheral tissues. Cell 2007; 131: 994-1008. [Crossref]

18. Abrams RA, McCormack K, Bowles C, Deisseroth AB. Cyclophosphamide treatment expands the circulating hematopoietic stem cell pool in dogs. Journal of Clinical Investigation 1981; 67: 1392-9. [Crossref]

19. Richman $C M$, Weiner RS, Yankee RA. Increase in circulating stem cells following chemotherapy in man. Blood 1976; 47: 1031-9.

20. Tan JK, O'Neill HC. Haematopoietic stem cells in spleen have distinct differentiative potential for antigen presenting cells. Journal of Cellular and Molecular Medicine 2010; 14: 2144-50. [Crossref]

21. Despars G, Ni K, Bouchard A, O'Neill TJ, O'Neill HC. Molecular definition of an in vitro niche for dendritic cell development. Experimental Hematology 2004; 32: 1182-93. [Crossref]

22. Despars G, O'Neill HC. Splenic endothelial cell lines support development of dendritic cells from bone marrow. Stem Cells 2006; 24 : 1496-504. [Crossref]

23. O'Neill HC, Wilson HL, Quah B, Abbey JL, Despars G, Ni K. Dendritic cell development in long-term spleen stromal cultures. Stem Cells 2004; 22: 475-86. [Crossref]

24. Periasamy P, Tan JK, Griffiths KL, O'Neill HC. Splenic stromal niches support hematopoiesis of dendritic-like cells from precursors in bone marrow and spleen. Experimental Hematology 2009; 37: 1060-71. [Crossref]

25. Tan JK, Periasamy P, O'Neill HC. Delineation of precursors in murine spleen that develop in contact with splenic endothelium to give 
novel dendritic-like cells. Blood. 2010; 115: 3678-85. [Crossref]

26. Tan JK, Quah BJ, Griffiths KL, Periasamy P, Hey YY, O'Neill HC. Identification of a novel antigen cross-presenting cell type in spleen. Journal of Cellular and Molecular Medicine 2011; 15: 1189-99. [Crossref]

27. Merad M, Manz MG, Karsunky H, Wagers A, Peters W, Charo l, et al. Langerhans cells renew in the skin throughout life under steadystate conditions. Nature immunology 2002; 3: 1135-41. [Crossref]

28. Ajami B, Bennett JL, Krieger C, TetzlaffW, Rossi FM. Local self-renewal can sustain CNS microglia maintenance and function throughout adult life. Nature neuroscience. 2007; 10: 1538-43. [Crossref]

29. Tan JKH, O'Neill HC. Myelopoiesis in spleen producing distinct dendritic-like cells Journal of Cellular and Molecular Medicine 2011. [Crossref]

30. Morita Y, Iseki A, Okamura S, Suzuki S, Nakauchi H, Ema H. Functional characterization of hematopoietic stem cells in the spleen. Experimental Hematology 2011; 39: 359-3. [Crossref]

31. Dennis JE, Charbord P. Origin and differentiation of human and murine stroma. Stem Cells 2002; 20: 205-14. [Crossref]

32. Zhang CC, Kaba M, lizuka S, Huynh H, Lodish HF. Angiopoietin-like 5 and IGFBP2 stimulate ex vivo expansion of human cord blood hematopoietic stem cells as assayed by NOD/SCID transplantation. Blood 2008; 111: 3415-23. [Crossref]

33. Blank U, Karlsson G, Karlsson S. Signaling pathways governing stemcell fate. Blood 2008; 111: 492-503. [Crossref]

34. Calvi LM, Adams GB, Weibrecht KW, Weber JM, Olson DP, Knight MC, et al. Osteoblastic cells regulate the haematopoietic stem cell niche. Nature 2003; 425: 841-6. [Crossref]

35. Zhang J, Niu C, Ye L, Huang H, He X, Tong WG, et al. Identification of the haematopoietic stem cell niche and control of the niche size. Nature 2003; 425: 836-41. [Crossref]

36. Bianco P. Bone and the hematopoietic niche: a tale of two stem cells. Blood 2011; 117: 5281-8. [Crossref]

37. Arai F, Hirao A, Ohmura M, Sato H, Matsuoka S, Takubo K, et al. Tie2/ angiopoietin-1 signaling regulates hematopoietic stem cell quiescence in the bone marrow niche. Cell 2004; 118: 149-61. [Crossref]

38. Chan CK, Chen CC, Luppen CA, Kim JB, DeBoer AT, Wei K, et al. Endochondral ossification is required for haematopoietic stem-cell niche formation. Nature 2009; 457: 490-4. [Crossref]

39. Sacchetti B, Funari A, Michienzi S, Di Cesare S, Piersanti S, Saggio I, et al. Self-renewing osteoprogenitors in bone marrow sinusoids can organize a hematopoietic microenvironment. Cell 2007; 131:324-36. [Crossref]

40. Sugiyama $T$, Kohara $H$, Noda $M$, Nagasawa T. Maintenance of the hematopoietic stem cell pool by CXCL12-CXCR4 chemokine signaling in bone marrow stromal cell niches. Immunity 2006; 25: 977-88. [Crossref]

41. Bautch VL. Stem cells and the vasculature. Nature medicine $2011 ; 17$ 1437-43. [Crossref]

42. Omatsu $Y$, Sugiyama $T$, Kohara $H$, Kondoh G, Fujii N, Kohno $K$, et al. The essential functions of adipo-osteogenic progenitors as the hematopoietic stem and progenitor cell niche. Immunity 2010; 33: 387-99. [Crossref]

43. Ding L, Saunders TL, Enikolopov G, Morrison SJ. Endothelial and perivascular cells maintain haematopoietic stem cells. Nature 2012; 481: 457-62. [Crossref]

44. Moore KA, Ema H, Lemischka IR. In vitro maintenance of highly purified, transplantable hematopoietic stem cells. Blood 1997; 89: 4337-47.
45. Wineman J, Moore K, Lemischka I, Muller-Sieburg C. Functional heterogeneity of the hematopoietic microenvironment: rare stromal elements maintain long-term repopulating stem cells. Blood 1996; 87: 4082-90.

46. Quah B, Ni K, O'Neill HC. In vitro hematopoiesis produces a distinct class of immature dendritic cells from spleen progenitors with limited T cell stimulation capacity. International Immunology 2004; 16 : 567-77. [Crossref]

47. Kiel MJ, Morrison SJ. Maintaining hematopoietic stem cells in the vascular niche. Immunity 2006; 25: 862-4. [Crossref]

48. Despars G, O'Neill HC. A role for niches in the development of a multiplicity of dendritic cell subsets. Experimental Hematology 2004; 32: 235-43. [Crossref]

49. Hinton RA, O'Neill HC. Technical Advance: In vitro production of distinct dendritic-like antigen-presenting cells from self-renewing hematopoietic stem cells. Journal of leukocyte biology 2012; 91:341-6. [Crossref]

50. Fritz JH, Gommerman JL. Cytokine/Stromal Cell Networks and Lymphoid Tissue Environments. Journal of interferon \& cytokine research: the official journal of the International Society for Interferon and Cytokine Research 2010.

51. Mueller SN, Germain RN. Stromal cell contributions to the homeostasis and functionality of the immune system. Nature reviews Immunology 2009; 9: 618-29.

52. Tan JK, O'Neill HC. Investigation of murine spleen as a niche for hematopoiesis. Transplantation 2010; 89: 140-5. [Crossref]

53. Shatry AM, Levy RB. Engraftment of splenic tissue as a method to investigate repopulation by hematopoietic cells from host and donor marrow. Stem cells and development 2004; 13: 390-9. [Crossref]

54. Shatry AM, Jones M, Levy RB. The effect of the spleen on compartmental levels and distribution of donor progenitor cells after syngeneic and allogeneic bone marrow transplants. Stem Cells Dev 2004; 13: 51-62. [Crossref]

55. Suematsu S, Watanabe T. Generation of a synthetic lymphoid tissuelike organoid in mice. Nature Biotechnology 2004; 22: 1539-45. [Crossref]

56. Tan JK, Watanabe T. Artificial engineering of secondary lymphoid organs. Advances in immunology 2010; 105: 131-57. [Crossref]

57. Grikscheit TC, Sala FG, Ogilvie J, Bower KA, Ochoa ER, Alsberg E, et al. Tissue-engineered spleen protects against overwhelming pneumococcal sepsis in a rodent model. The Journal of surgical research 2008; 149: 214-8. [Crossref]

58. Timmermans F, Plum J, Yoder MC, Ingram DA, Vandekerckhove B, Case J. Endothelial progenitor cells: identity defined? Journal of Cellular and Molecular Medicine 2009; 13: 87-102. [Crossref]

59. Hristov M, Erl W, Weber PC. Endothelial progenitor cells: isolation and characterization. Trends in cardiovascular med. 2003; 13: 201-6. [Crossref]

60. Purhonen S, Palm J, Rossi D, Kaskenpää N, Rajantie I, Ylä-Herttuala $\mathrm{S}$, et al. Bone marrow-derived circulating endothelial precursors do not contribute to vascular endothelium and are not needed for tumor growth. Proceedings of the National Academy of Sciences of the United States of America 2008; 105: 6620-5. [Crossref]

61. Villaron EM, Almeida J, López-Holgado N, Alcoceba M, SánchezAbarca LI, Sanchez-Guijo FM, et al. Mesenchymal stem cells are present in peripheral blood and can engraft after allogeneic hematopoietic stem cell transplantation. Haematologica 2004; 89: 1421-7. 